\title{
Heart block resulting from myocardial sarcoidosis
}

\author{
F. J. Fawcett and M. J. Goldberg \\ From the Department of Pathology, Peterborough District Hospital, Peterborough, and Leicester Regional \\ Cardio-thoracic Unit, Groby Road Hospital, Leicester
}

The clinical and pathological findings in a 60-year-old man with complete heart block are described. He died as a result of pacemaker failure, and necropsy showed massive myocardial involvement by sarcoidosis which had destroyed the atrioventricular node and upper part of the bundle of His. There was no clinical evidence of sarcoidosis.

Myocardial sarcoidosis is a relatively uncommon cause of heart block. In their review of the published reports in 1968, Bashour et al. could only collect 45 cases of proven sarcoidosis in whom death was due to this pathology. Of these cases, 35 had electrocardiographic studies before death, and complete heart block was shown in 14 of them. On the basis of necropsy findings, the incidence of myocardial involvement in cases of sarcoidosis ranges from 13 to 20 per cent (Longcope and Freiman, 1952; Mayock et al., 1963; Branson and Park, 1954). However, H. A. Fleming (1972, personal communication) from his own personal experience and having collected the data of cases from several centres in the British Isles, and having written to a large number of cardiac and thoracic centres, has shown that the condition is probably more frequent than generally thought.

This report describes a case with extensive myocardial sarcoidosis but little involvement of other organs.

\section{Case report}

A 60-year-old European farmer, who had previously been healthy, was diagnosed as having complete heart block in June 1971 after the onset of recurrent bouts of faintness and syncope, and of severe breathlessness on effort. He was initially treated with long-acting oral isoprenaline tablets (Saventrine) which abolished the bouts of syncope. However, he developed urinary retention from an enlarged prostate gland, and as it was considered that a prostatectomy was necessary, he was referred for the insertion of a pacemaker in September I97I.

He was found to be in complete heart block with a heart rate of 40 per minute. There were no signs of cardiac failure, the heart was not clinically enlarged, and there were no cardiac murmurs. Blood pressure was 140/70 mmHg. The liver, spleen, and lymph nodes were not enlarged, and there were no rashes. Except for diffuse enlargement of the prostate, the rest of the examination was normal.

The electrocardiogram showed complete heart block with a ventricular rate of $40 \mathrm{a}$ minute, and a $Q R S$ pattern of left anterior hemiblock and right bundle-branch block. The chest $x$-ray showed slight cardiac enlargement, but the lung fields were normal and mediastinal lymph node enlargement could not be seen. The full blood count, erythrocyte sedimentation rate, blood electrolytes, and blood urea were normal. A trace of albumin was present in the urine, but urine microscopy and culture showed no abnormality.

A pacemaker was inserted, pacing being carried out by the endocardial route with a St. George's catheter electrode, and a fixed rate Devices Thin Film pacemaker (type 3821). In October 197I a prostatectomy was uneventfully carried out.

After his prostatectomy he was asymptomatic, and pacing tests on the 28 October 1971 showed satisfactory pacing and pacemaker function. However, on the 22 December I97I, he died suddenly while sitting at home after a day's shooting. The pacemaker was removed at necropsy and was found to have failed.

\section{Necropsy}

The body was that of a well-nourished elderly man and there were no significant external findings. The pacemaker coil was implanted in the anterior abdominal wall; the catheter ran up to the right jugular vein and down into the apex of the right ventricle, and was intact throughout its length. The lungs showed small old calcified tuberculous lesions at the apex of both lungs but no other abnormalities. The lymph nodes around both main bronchi were enlarged (largest $2 \times 2 \times 1.5 \mathrm{~cm}$ ) and had a fleshy texture. The heart, $490 \mathrm{~g}$, showed numerous white fleshy nodules involving the walls of all the cavities, but the left ventricular wall and interventricular septum were most severely involved, with nodules up to $3.5 \times 3 \times 1.5 \mathrm{~cm}$ (Fig. I). The upper part of the interventricular septum was infil- 


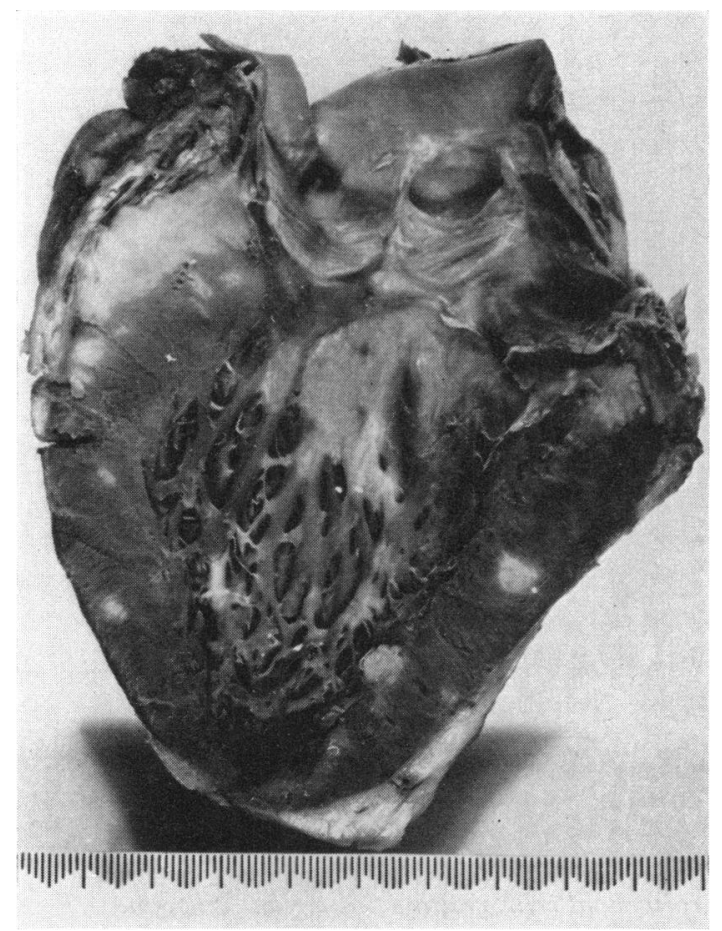

FIG. I Left ventricle showing extensive infiltration of wall and interventricular septum by sarcoidosis.

trated throughout the majority of its breadth and depth, as was the adjacent interatrial septum including the atrioventricular node and the upper part of the bundle of His.

The papillary muscles were also involved, more in the right than in the left ventricle. Many of the nodules extended from the pericardium to the endocardium and there were also plaques primarily involving the endocardium and adjacent myocardium. There was an area of dense fibrosis, $3 \mathrm{~mm}$ in diameter, of the papillary muscles at the apex of the right ventricle around the tip of the catheter. The mitral valve showed thickening of the cusps but no adhesions of the commissures; the other heart valves were normal. The coronary arteries showed minimal atheroma with only a minor degree of stenosis. The only other abnormal findings were similar fleshy masses in the kidneys mainly in the subcapsular area (maximal diameter $1.5 \mathrm{~cm}$ ) which were otherwise normal (total weight $300 \mathrm{~g}$ ). The eyes and parotid glands were not examined in detail at the time of necropsy but their external appearance was normal.

\section{Histology}

The fleshy nodules in the heart, mediastinal lymph nodes, and kidneys showed non-caseating granulomatous lesions with many epithelioid cells and multinucleate giant cells surrounded by a cuff of lymphocytes (Fig. 2). There were asteroids present in some of the giant cells in all affected organs but no Schaumann bodies were seen. No organisms could be demonstrated in the lesions, neither was any organism grown on culture of the fresh myocardial lesions. In the heart, many of the lesions were surrounding small arteries but the wall was not infiltrated and the lumen was not stenosed. There was a variable amount of hyaline fibrous tissue around the lesions. There were granulomatous lesions at the base of the mitral and aortic valve cusps but only fibrous thickening of the cusps with a few lymphocytes in the mitral valve cusps and no cells in the aortic cusps. The superior vena cava was encased by the granulomatous reaction for approximately $\mathrm{I} \mathrm{cm}$ above the right atrium, but the other great vessels were not involved. Sections from the other organs which appeared normal macroscopically were free from granulomas.

\section{Discussion}

Myocardial sarcoidosis is a relatively rare condition, the first case being recorded in 1929 (Bernstein, Konzlemann, and Sidlick, 1929). The condition has recently been reviewed by Ghosh et al. (1972) and Gozo et al. (197I).

It may present clinically in the following ways.

a) Disturbances of rhythm are the most common presenting features, and complete heart block is the most frequent and important dysrhythmia. This is explained by the frequent involvement of the ventricular septum. Of the 29 cases of myocardial sarcoidosis reviewed by Peacock, Lippshutz, and Lukas (1957), I5 cases suffered Adams-Stokes attacks or had complete heart block. Ventricular tachycardia, atrial fibrillation, and atrial tachycardia are less frequent manifestations.

b) Sudden death is common in myocardial sarcoidosis and is frequently the first manifestation of the condition. However, it is possibly a manifestation of severe disturbances of the conductive system.

c) Congestive cardiac failure, which may be a manifestation of severe rhythm disturbances or of impairment of cardiac contractility, caused by ventricular infiltration.

d) Miscellaneous: valve involvement (Raftery, Oakley, and Goodwin, 1966; Simkins, I95I; Laroche et al., 1955) and recurrent pericardial effusions (Shiff, Blatt, and Colp, 1969) have been reported but are rare.

The present case presented with complete heart block without any other manifestations of sarcoidosis to suggest an underlying myocardial pathology. There was no radiological evidence of hilar lymph node enlargement. It is of interest that he responded well initially to oral isoprenaline, and that he was well controlled by his pacemaker. There is one previous report of control of complete heart block 


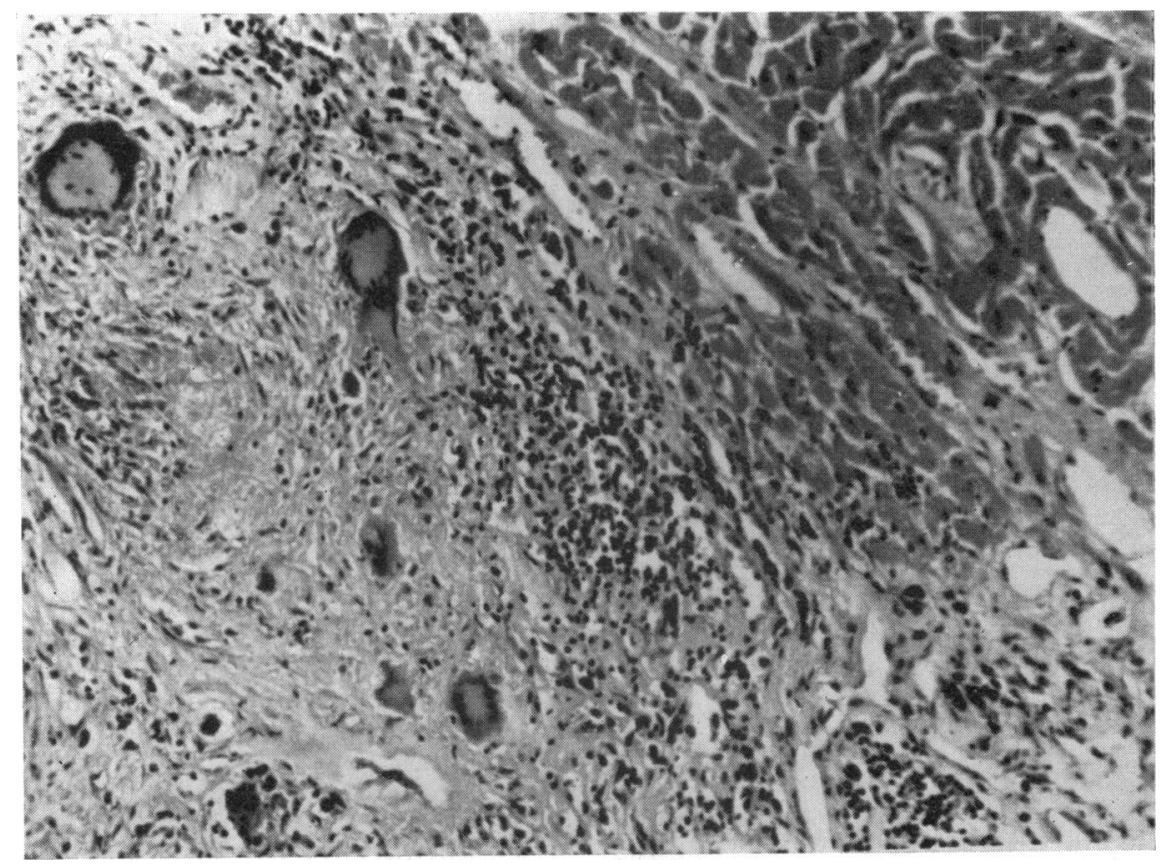

FIG. 2 Sarcoid granuloma in myocardium with epithelioid cells, multinucleate giant cells, and lymphocytes. $(\times 350$.

with a pacemaker (Johansen, 1966). The patient was diagnosed clinically as having sarcoidosis because of typical chest $x$-ray appearances 8 years before the development of complete heart block. The heart block was successfully treated with an internal pacemaker for 31 months, but he suddenly died from pacemaker failure. Sarcoid granulomas were demonstrated in the ventricular septum.

In one of Phinney's cases (196I) pacemaking was probably of the external, transthoracic type, and so cannot be quoted as a failure of pacing as has been done in previous reviews.

In most reported cases, the left ventricle and interventricular septum were predominantly involved, but the present case shows an unusual degree of left atrial involvement. The lesions are most frequently seen around small blood vessels in the myocardium. Frequently the granulomas are atypical in the myocardium, presenting as a nonspecific granuloma or a patchy hyaline fibrosis with little specific epithelioid and giant cell granuloma formation, though other organs contain better defined sarcoid tubercules (Scadding, 1967). In the present case the granulomas were florid and of a typical sarcoid appearance.

\section{References}

Bashour, F. A., McConnell, T., Skinner, W., and Hanson, M. (1968). Myocardial sarcoidosis. Diseases of the Chest, 53, 413.

Bernstein, M., Konzlemann, F. W., and Sidlick, D. M. (I929) Boeck's sarcoid; report of a case with visceral involvement. Archives of Internal Medicine, 44, 72r.

Branson, J. H., and Park, J. H. (1954). Sarcoidosis - hepatic involvement: presentation of a case with fatal liver involvement, including autopsy findings and review of the evidence for sarcoid involvement of the liver as found in the literature. Annals of Internal Medicine, 40, I I 1 .

Ghosh, P., Fleming, H. A., Gresham, G. A., and Stovin, P. G. I. (1972). Myocardial sarcoidosis. British Heart Fournal, 34, 769 .

Gozo, E. G., Cosnow, I., Cohen, H. C., and Okun, L. (1971). The heart in sarcoidosis. Chest, 60, 379.

Johansen, A. (1966). Isolated myocarditis versus myocardial sarcoidosis. Acta Pathologica et Microbiologica Scandinavica, 67, 15 .

Laroche, C., Gennes, J. L. De, Hazard, J., and Samarcq, P. (1955). Maladie de Besnier - Boeck - Schaumann avec manifestations polyarticulaires et localizations endo-myopéricardiques mortelles. Bulletins et Mémoires de la Société Médicale des hôpitaux de Paris, 71, 908.

Longcope, W. T., and Freiman, D. G. (1952). A study of sarcoidosis based on a combined investigation of 160 cases including 30 autopsies from the Johns Hopkins Hospital and Massachusetts General Hospital. Medicine, 3I, I. 
Mayock, R. L., Bertrand, P., Morrison, C. E., and Scott, J. H. (1963). Manifestations of sarcoidosis. Analysis of 145 patients with a review of 9 series selected from the literature. American fournal of Medicine, 35, 67.

Peacock, R. A., Lippshutz, E. J., and Lukas, A. (1957). Myocardial sarcoidosis. Circulation, 16, 67.

Phinney, A. O. (I96I). Sarcoid of the myocardial septum with complete heart-block - report of 2 cases. American Heart fournal, 62, 270.

Raftery, E. B., Oakley, C. M., and Goodwin, J. F. (1966). Acute subvalvar mitral incompetence. Lancet, 2, 360 .

Scadding, J. G. (1967). Sarcoidosis, p. 291. Eyre and Spottiswood, London.
Shiff, A. D., Blatt, C. J., and Colp, C. (1969). Recurrent pericardial effusion secondary to sarcoidosis of the pericardium. New England fournal of Medicine, 281, 141.

Simkins, S. (I95I). Boeck's sarcoid with complete heart block mimicking carotid sinus syncope. Fournal of the American Medical Association, 146, 794.

Requests for reprints to Dr. F. J. Fawcett, Pathology Department, Peterborough District Hospital, Midland Road, Peterborough $\mathrm{PE}_{3}$ 6DA. 